\title{
Influence of basalt micro-fibres on the abrasion resistance of concrete in hydraulic structures
}

\author{
Nicholas Omoding • Lee S. Cunningham • Gregory F. Lane-Serff
}

Received: 8 June 2020/ Accepted: 9 February 2021/Published online: 8 March 2021

(C) The Author(s) 2021

\begin{abstract}
In hydraulic structures, abrasion resistance can be a significant driver in concrete specification. Basalt micro-fibres represent a potentially sustainable construction product and have been shown to provide various benefits in concrete, however the implications for hydrodynamic abrasion resistance are to date unclear. This paper is the first investigation of its kind to examine the abrasion resistance of basalt fibrereinforced (BFR) concretes using the ASTM C1138 underwater test method. Towards this, concretes incorporating fibre dosages of $0.5,1,1.5$ and $3 \mathrm{~kg} /$ $\mathrm{m}^{3}$ were tested. The relationships between concrete abrasion and its fundamental mechanical properties are evaluated. For the particular concretes examined, it is found that based on the Shapiro-Wilks tests at 95\% confidence, abrasion loss in BFR concretes followed a normal distribution; the use of basalt fibre in contents of up to $3 \mathrm{~kg} / \mathrm{m}^{3}$ did not have a significant effect on abrasion resistance, compressive and tensile splitting strengths, as well as modulus of elasticity. It can be concluded that basalt micro-fibre can be used for their other attributes such as controlling bleeding, shrinkage and plastic cracking in concrete hydraulic structures without deleterious effects on abrasion resistance. The regression models proposed to predict concrete abrasion loss from its mechanical properties were found to
\end{abstract}

N. Omoding $(\varangle) \cdot$ L. S. Cunningham · G. F. Lane-Serff Department of Mechanical, Aerospace and Civil Engineering, University of Manchester, Manchester, UK e-mail: nicholas.omoding@manchester.ac.uk be only significant at $48 \mathrm{~h}$ for compressive strength and $24 \mathrm{~h}$ for both tensile splitting strength and modulus of elasticity.

Keywords Basalt fibre $\cdot$ Concrete abrasion resistance $\cdot$ Hydraulic structures $\cdot$ Statistical significance

\section{Introduction}

Concrete is an important material in the construction of hydraulic structures. In recent years, the use of steel, glass, polymer fibres, etc. to reinforce cement-based composites has increased considerably. The choice of an appropriate fibre type for concrete depends on the properties to be influenced. Macro-fibres which have typical diameters from 0.3 to $1.0 \mathrm{~mm}$, and length in the range of 12-65 $\mathrm{mm}$ have been shown to improve the post-cracking ductility of concrete, particularly in the case of steel macro-fibres. Investigations on the influence of steel macro-fibres on the abrasion resistance of concrete [1-4] have yielded inconsistent results. Liu and McDonald [1] and Sharma et al. [4] reported reductions in abrasion resistance due to addition of steel fibres while Sonebi and Khayat [2] found the influence of steel fibre on abrasion resistance to be insignificant. However, Horszczaruk [3] found improvements of up to $19 \%$ when using steel fibres with aspect ratios of over 50. Although steel fibres 
possess a high modulus of elasticity and stiffness, their application in hydraulic concrete structures is limited by their susceptibility to corrosion and relatively high density which can increase the self-weight of steel fibre-reinforced concrete [5]. In parallel with this, when steel fibres become exposed during the abrasion process, they may present a safety hazard in areas of public accessibility e.g. coastal defences.

In contrast, micro-fibres have typical diameters in the range of $0.01-0.3 \mathrm{~mm}$, with lengths of 3-50 $\mathrm{mm}$ [6] and are introduced to reduce the rate of bleeding in fresh concrete $[7,8]$ and control to plastic and drying shrinkage cracking $[6,9]$. Polymer-based fibres often produced from polyolefin, such as polypropylene fibres exhibit both a low elastic modulus and melting points $[5,6]$. On other hand, glass fibre use in concrete is discouraged by its vulnerability to degradation in the alkaline concrete environment [5].

Several studies suggest that basalt fibres have the potential to overcome the drawbacks of steel, glass and polymer-based fibres. Basalt fibres (BF) are produced from basalt which is a dark-coloured, finegrained igneous rock characterised by high strength, hardness, and mainly composed of plagioclase and pyroxene minerals [10]. The manufacturing process for BF uses basalt rock as a raw material which is melted and pressured through rhodium or platinum crucibles in a process termed as continuous spinning to produce either continuous or chopped fibre forms [11]. The fact that no additives are introduced and less energy is consumed in the production process of $\mathrm{BF}$ contributes to reduced cost relative to similar-sized glass fibres [12]. Table 1 shows that BF exhibit excellent mechanical properties such as higher tensile strength and modulus of elasticity in comparison to polymeric fibre types like polypropylene (PP) and polyvinyl alcohol (PVA). BF have also been reported to exhibit high chemical stability, durability in acid and alkaline environments, as well as a large operating temperature range of $-200{ }^{\circ} \mathrm{C}$ to $800{ }^{\circ} \mathrm{C}$ [11] compared to some polymeric fibres which exhibit melting temperatures of $160{ }^{\circ} \mathrm{C}[3,13]$.

Many past studies on BF-reinforced concretes [5, 14-17, 22-24] have focused on the effects of BF addition on its fundamental mechanical properties such as strengths (compressive, tensile splitting, flexural and impact), modulus of elasticity, loaddisplacement behaviour, fracture energy and toughness. In hydraulic structures exposed to flows laden with hard sediments, abrasion can occur [25] which severely degrades concrete surfaces and hence reduces their service life and safety [26-30]. Thus, the selection of concrete mixtures to be used in these structures is often governed by abrasion resistance [29]. There are several test methods for abrasion resistance [13, 31, 32] but the ASTM C1138 [32] has been shown to be the most suitable method for the evaluation of concrete performance in abrasive hydraulic environments [30,33]. This is because it is able to produce concrete surfaces that are qualitatively similar to those observed in field conditions, i.e. stilling basins of hydro-electric power schemes [28] and concrete coastal defence elements [29]. This indicates that this test method adequately simulates the most relevant mechanisms of concrete abrasion in the field [30]. Table 2 summarises the limited past studies on the effects of different micro-fibre types on the abrasion resistance of concrete.

Table 2 shows that regardless of the test method used, PP and PVA micro-fibre additions enhanced the abrasion resistance of mortars and concrete by $20 \%-$ $95 \%$ [18, 19], and 6\%-29\% [3, 13] respectively. Similarly, the addition of basalt micro-fibre in mortar and concrete mixtures also improved abrasion resistance by $14 \%-39 \%$ [18] and 2\%-18\% [17] respectively. These findings indicate that there is generally some improvement in the abrasion resistance of concrete when both polymeric and basalt micro-fibres

Table 1 Characteristics of the fibres used in concrete

\begin{tabular}{lllll}
\hline Fibre type & Density $\left(\mathrm{kg} / \mathrm{m}^{3}\right)$ & Tensile strength (MPa) & Modulus of elasticity (MPa) & Elongation (\%) \\
\hline Basalt [5, 14-17] & $2630-2800$ & $3000-4800$ & $80-110$ & $3.1-3.2$ \\
Polypropylene [3, 5, 13, 15, 18] & 910 & $247-700$ & $4-9$ & $9.0-12.9$ \\
Polyvinyl alcohol [19-21] & $1290-1300$ & $1400-1620$ & $32-43$ & $6.0-7.0$ \\
Glass [16] & 2600 & 3400 & 77 & 2.6 \\
Steel [15] & 7860 & 2850 & 201 & - \\
\hline
\end{tabular}


Table 2 Existing past studies on abrasion resistance of mortars and concretes

\begin{tabular}{|c|c|c|c|c|}
\hline Study description & Variable & Aggregates & Fibre properties & Conclusion \\
\hline $1=$ Author $(s)$ & $1=\mathrm{CS}$ & 1 = FA type $(\mathrm{s})$ & $1=$ Type $/$ Dose $\left(\mathrm{kg} / \mathrm{m}^{3}\right)$ & $\begin{array}{l}\% \text { increase in abrasion } \\
\text { resistance }\end{array}$ \\
\hline $2=$ Test method & $2=w / c$ & $2=\mathrm{FA}$ dose $\left(\mathrm{kg} / \mathrm{m}^{3}\right)$ & $2=\phi /$ Length $(\mu \mathrm{m} / \mathrm{m})$ & \\
\hline $3=\operatorname{Age}(\mathrm{s})$ & $3=\mathrm{SP}$ & $3=$ CA type $\left(\mathrm{kg} / \mathrm{m}^{3}\right)$ & $3=\mathrm{TS}(\mathrm{MPa})$ & \\
\hline $4=$ Curing & & $4=\mathrm{CA}$ size $(\mathrm{mm}) /$ dose $\left(\mathrm{kg} / \mathrm{m}^{3}\right)$ & $4=\mathrm{ME}(\mathrm{GPa})$ & \\
\hline \multirow[t]{2}{*}{$5=\mathrm{CS}$ specimen } & & $5=$ Binder(s) type & & \\
\hline & & $6=$ Binder content & & \\
\hline $1=$ Abid et al. $[19]^{\mathrm{a}}$ & $1=47-48$ & $1=$ Silica sand & $1=$ PVA/6.5-26 & +20 to 95 \\
\hline $2=$ ASTM C1138 [32] & $2=0.26$ & $2=455$ & $2=39 / 6$ & \\
\hline $3=3,7,28$ days & $3=0.9$ & $3=$ None & $3=1620$ & \\
\hline $4=$ Water $\left(23^{\circ} \mathrm{C}\right)$ & & $4=$ None & $4=43$ & \\
\hline $5=100 \mathrm{~mm}$ cubes & & $\begin{array}{l}5=\text { OPC; Fly ash } \\
6=570 ; 684\end{array}$ & & \\
\hline $1=$ Jiang et al. $[18]^{\mathrm{a}}$ & $1=52-54$ & $1=$ River sand & $1=$ Basalt $/ 0.6-2.6$ & +14 to 39 \\
\hline 2 = ASTM C1138 [32] & $2=0.54$ & $2=1362$ & $2=13 / 20$ & \\
\hline $3=28$ days & $3=0.2$ & $3=$ None & $3=624$ & \\
\hline $4=$ Room at $20^{\circ} \mathrm{C}$ & & $4=$ None & $4=101.5 \pm 8.5$ & \\
\hline \multirow[t]{4}{*}{$5=40 \mathrm{~mm}$ cubes } & $1=53-56$ & $5=\mathrm{OPC}$ & $1=\mathrm{PP} / 0.6-2.6$ & \\
\hline & $2=0.54$ & $6=680$ & $2=50 / 4-19$ & +25 to 77 \\
\hline & $3=0.2$ & & $3=500$ & \\
\hline & & & $4=3.5$ & \\
\hline 1 = Kabay [17] & $1=45-49$ & 1 = River sand; limestone & $1=$ Basalt $/ 2$ and 4 & +14 to 18 \\
\hline $2=$ Bohme $[31]$ & $2=0.60$ & $2=520-563$ & $2=12-20 / 12$ and 24 & +2 to 4 \\
\hline $3=28$ days & $3=0.3-0.8$ & $3=$ Limestone & $3=4100-4800$ & \\
\hline $4=$ Water $\left(20 \pm 2^{\circ} \mathrm{C}\right)$ & $1=59-69$ & $4=11.2 / 714-771$ & $4=89$ & \\
\hline \multirow[t]{2}{*}{$5=100 \mathrm{~mm}$ cubes } & $2=0.45$ & $5=\mathrm{CEM}$ I 42.5R & & \\
\hline & $3=1.8-2.7$ & $6=350$ & & \\
\hline $1=$ Horszczaruk [3] & $1=98-100$ & $1=$ Natural sand & $1=\mathrm{PP} / 1.8$ & +29 \\
\hline $2=$ ASTM C1138 [32] & $2=0.30$ & $2=535$ & $2=$ Not stated $/ 19$ & \\
\hline $3=28$ days & $3=1.0$ & $3=$ Basalt & $3=310$ & \\
\hline $4=$ Water $\left(20 \pm 2^{\circ} \mathrm{C}\right)$ & & $4=16 / 1279$ & $4=$ Not stated & \\
\hline \multirow[t]{2}{*}{$5=100 \mathrm{~mm}$ cubes } & & $5=$ CEM 1 52.5R; SF & & \\
\hline & & $6=450 ; 45$ & & \\
\hline $1=$ Grdic et al. [13] & $1=38$ & $1=$ River aggregate & $1=\mathrm{PP} / 0.9$ & +7 \\
\hline $\begin{array}{l}2=\text { Water/sand jet }(10: 1) \\
\text { at } 20 \mathrm{~m} / \mathrm{s}\end{array}$ & $2=0.7$ & $2=775-882$ & $2=37 / 12$ & +6 \\
\hline \multirow[t]{4}{*}{$5=150 \mathrm{~mm}$ cubes } & $1=27$ & $3=$ River aggregate & $3=301 \pm 32$ & +7 \\
\hline & $2=0.6$ & $4=16 / 948-1005$ & $4=$ Not stated & \\
\hline & $1=18$ & $5=\mathrm{CEM}$ I 42.5R & & \\
\hline & $2=0.5$ & $6=344-366$ & & \\
\hline
\end{tabular}

$\overline{C S}$ Compressive strength; TS Tensile strength; ME Modulus of elasticity; SP Superplasticiser; $C A$ Coarse aggregate; FA Fine aggregate; PP Polypropylene; PVA Polyvinyl alcohol; SF Silica fume; $w / c$ Water to cement ratio

Polycarboxylate-based SPs were general adopted with exception of Jiang et al. [18] in which sulfonated naphthalene-formalde-hyde was used

${ }^{\mathrm{a}}$ Mortar mixtures 
are incorporated into mixtures. Despite the many benefits of $\mathrm{BF}$, it is evident that existing research on the abrasion resistance of BF-reinforced cement composites has been limited tests on mortars using the ASTM C1138 method [18] and concrete mixtures using Bohme method [31]. Results from tests on mortars do not account for effect of coarse aggregates which also greatly affects concrete abrasion resistance $[29,34,35]$ whilst the Bohme test does not adequately simulate concrete abrasion in hydraulic structures [36]. To date, there are no readily available published studies that have investigated the abrasion resistance of BFR concretes using the ASTM C1138 test method. Further, most of the reported increases in abrasion resistance of BF-reinforced mortars and concretes seem to be negligible given that measured abrasion losses in concretes exhibit inherent deviations with coefficients of variations of up to $30 \%$ in the case of the ASTM C1138 test method [2, 34] which casts doubt on the significance of the reported enhancements in concrete abrasion resistance.

The objective of this study is to undertake a statistical evaluation of the ASTM C1138 abrasion test results to determine the effect of basalt micro-fibre use on concrete resistance. Further, the relationship between abrasion loss and fundamental mechanical properties of concrete i.e. compressive strength, tensile splitting strength and modulus of elasticity is comparatively examined. The understanding of the significance of the effect of basalt fibre addition on the abrasion resistance of concrete is crucial for reliable specification of concrete mixtures used in hydraulic structures exposed to abrasive flows. Also, establishing the variation of concrete abrasion with mechanical properties is important for prediction of its performance in the ASTM C1138 test without expensive abrasion tests.

\section{Experimental plan}

\subsection{Materials}

\subsubsection{Basalt fibre}

The study used chopped basalt micro-fibre bundles shown in Fig. 1. The length, diameter, tensile strength and modulus of elasticity of each fibre filament as provided by the supplier were $25.4 \mathrm{~mm}, 17$ microns,
$3050 \pm 150 \mathrm{MPa}$ and $87 \pm 2 \mathrm{GPa}$ respectively. The fibres were dispersed into individual filaments during concrete mixing.

\subsubsection{Cement}

This was manufactured in accordance with the requirements of BS EN 197-1 [37] for CEM II/A-L $42.5 \mathrm{~N}$ was used throughout the study. CEM II/A-L $42.5 \mathrm{~N}$ is a blended cement obtained by replacing up to $20 \%$ of Portland cement with finely ground limestone.

\subsubsection{Aggregates}

The coarse aggregates used were uncrushed bunter quartzite particles in which $75 \%$ of the proportion comprised of orthoquartzite whilst the rest were particles derived from sedimentary and igneous rocks. The respective values of Mohs hardness, water absorption and relative density of the coarse aggregates were 7, 0.6 and 2.59. The particle shapes ranged from sub-rounded to rounded and the gradation followed the conditions of BS EN 12620 [38] for $10 \mathrm{~mm}$ maximum size of aggregate.

Natural River sand with a maximum particle size of $4 \mathrm{~mm}$, water absorption of $0.5 \%$ and relative density of 2.62 was used as fine aggregates. The sand complied with the particle size distribution required by BS EN 12620 [38] for fine aggregates with a maximum particle size of $4 \mathrm{~mm}$.

The gradating curves of coarse and fine aggregates used is presented in Fig. 2.

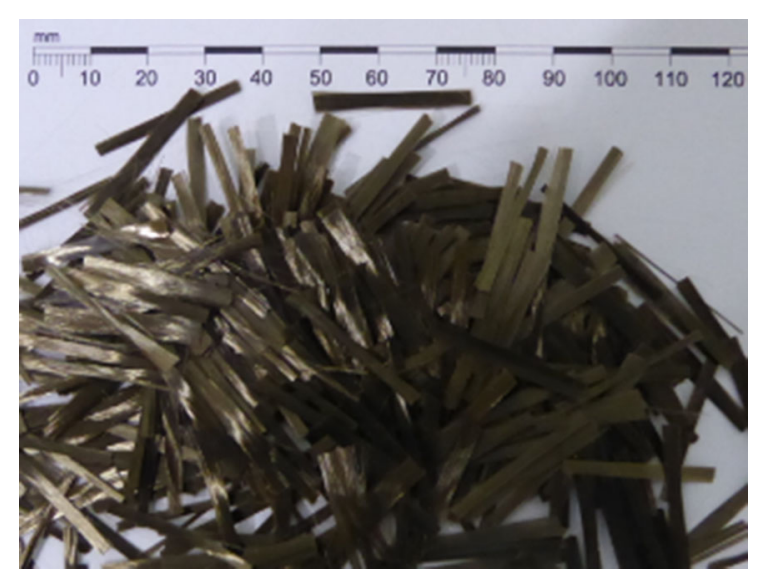

Fig. 1 Chopped basalt micro-fibre used 


\subsubsection{Water}

Ordinary tap water free from deleterious materials was used for concrete production.

\subsection{Test specimens}

\subsubsection{Concrete mix design}

The five concrete mixtures used in the study were proportioned to enable the effect of different basalt fibre (BF) dosages on the abrasion resistance of concrete to be investigated. The reference concrete (without BF) was designed to achieve the target cube compressive strength of $45 \mathrm{MPa}$ following the guidance provided by Building Research Establishment [39]. This mixture, designated as $\mathrm{RC} 0$ had a water to cement ratio $(w / c)$ of 0.52 , cement, fine and coarse aggregate contents of 423, 706 and $976 \mathrm{~kg} / \mathrm{m}^{3}$ respectively. Although BS 6349-1-4 [40] recommends the maximum $w / c$ as 0.45 for concrete mixtures used in abrasive marine environments, a slightly higher $w / c$ was adopted in this study to ensure that the coarse aggregate phase was harder than the matrix. This is because the effect of basalt fibre on concrete is related to its impact on the matrix phase and could be decisively determined when the matrix is more vulnerable to abrasion damage. Such a mixture also lent itself to the evaluation of whether or not basalt fibre addition can be used to improve the abrasion resistance of concretes with high $w / c$. Basalt fibre-reinforced concretes were derived from the control mixture by adding fibre in dosages of 0.5 , $1.0,1.5,3.0 \mathrm{~kg} / \mathrm{m}^{3}$ to obtain concretes mixtures FC0.5, FC1.0, FC1.5 and FC3.0 respectively.

Before test specimens were fabricated, slumps of selected mixtures was measured from the trial mixes in accordance with BS EN 12350-2 [41] to determine concrete workability. The slumps obtained for concretes RC0, FC0.5, FC1.0, FC1.5 and FC3.0 were 70,

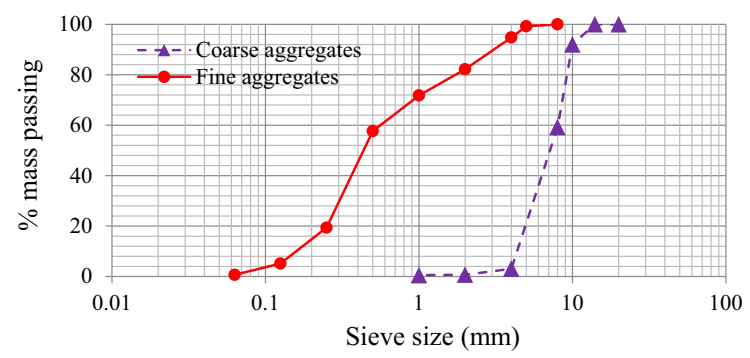

Fig. 2 Grading of coarse and fine aggregates used
$60,40,30$ and $30 \mathrm{~mm}$ respectively. These results indicate that incorporation of basalt fibre reduced concrete workability, and the degree of reduction increased with fibre content.

\subsubsection{Specimen fabrication}

The concrete test specimens for abrasion resistance $(295 \Phi \times 100 \mathrm{~mm}$ disc $)$, tensile strength and modulus of elasticity tests $(100 \Phi \times 200 \mathrm{~mm}$ cylinders $)$ were all fabricated in triplicate. For compressive strength testing, 9 cubes of $100 \mathrm{~mm}$ sides were prepared, 3 accompanying each separately cast concrete abrasion disc test specimen. The following procedure was adopted for specimen fabrication. The materials were batched according to the proportions outlined in Sect. 2.2.1 and mixed in a drum mixer. It was observed that $\mathrm{BF}$ was well-dispersed in the fresh concrete and the fact that no fibre balling was visible demonstrated the appropriateness of the BF contents and the thoroughness of the concrete mixing process used. The fresh concrete was then placed in lubricated moulds in approximately equal three layers and each layer compacted with the aid of a vibrating table. The exposed fresh concrete surfaces of the specimens were finished neatly using a steel float and covered with a sheet of polythene to reduce the rate of moisture escape. For the next $24 \mathrm{~h}$, the test specimens were kept in a room at temperature of $20 \pm 3{ }^{\circ} \mathrm{C}$, and after this period, were removed from the moulds and cured in water until the test age of 28 days.

\subsection{Test procedures}

\subsubsection{Abrasion resistance}

The ASTM C1138 method [32] whose experimental setup is illustrated in Fig. 3 was used to evaluate the abrasion resistance of concrete from a total of 15 concrete discs, three for each concrete mixture.

In this test method, the concrete disc specimen is submerged in water contained in a steel cylinder with a diameter of $300 \mathrm{~mm}$. Thereafter, the specimen is subjected to abrasion by 70 steel chrome balls with diameters of $25.4 \mathrm{~mm}$ (10 Nos), $19.1 \mathrm{~mm}$ (35 Nos) and $12.7 \mathrm{~mm}$ ( $25 \mathrm{Nos}$ ) that are moved by water agitated by a paddle rotating at $1200 \mathrm{rpm}$. The volume of the abraded concrete specimen, $V_{\mathrm{t}}$ at durations, $t$ of 24,48 and $72 \mathrm{~h}$ is calculated as, 
$V_{\mathrm{t}}=\frac{M_{\mathrm{a}}-M_{\mathrm{w}}}{\rho_{\mathrm{w}}}$.

In Eq. (1), $M_{\mathrm{a}}$ and $M_{\mathrm{w}}$ are the masses in air and water of the test specimen to the nearest $1 \mathrm{~g}$ for a specific time increments while $\rho_{\mathrm{w}}$ is the assumed density of water $\left(1000 \mathrm{~kg} / \mathrm{m}^{3}\right)$.

At a particular time increment, concrete abrasion loss $\left(V_{\mathrm{abr}}\right)$ is estimated as,

$V_{\mathrm{abr}}=V_{0}-V_{t}$.

In Eq. (2), $V_{\mathrm{o}}$ is the specimen volume prior to the test whilst $V_{\mathrm{t}}$ is the volume at a selected test duration. The measured concrete abrasion loss at 24, 48 and $72 \mathrm{~h}$ was presented as a percentage of the initial volume of the specimen.

In all tests, the bottom as-struck surfaces of test specimens were abraded to ensure that the quality of the concrete surface finish and the density was similar to those of coastal revetment armour units. These are commonly precast units that are cast face-down so the abraded surface is that which was originally in direct contact with the mould [29, 42, 43]. This is done so that a dense and high-quality-finished surface is the one that is exposed to the aggressive conditions. This helps to reduce the risk of ingress of deleterious sulphates and chlorides [42].

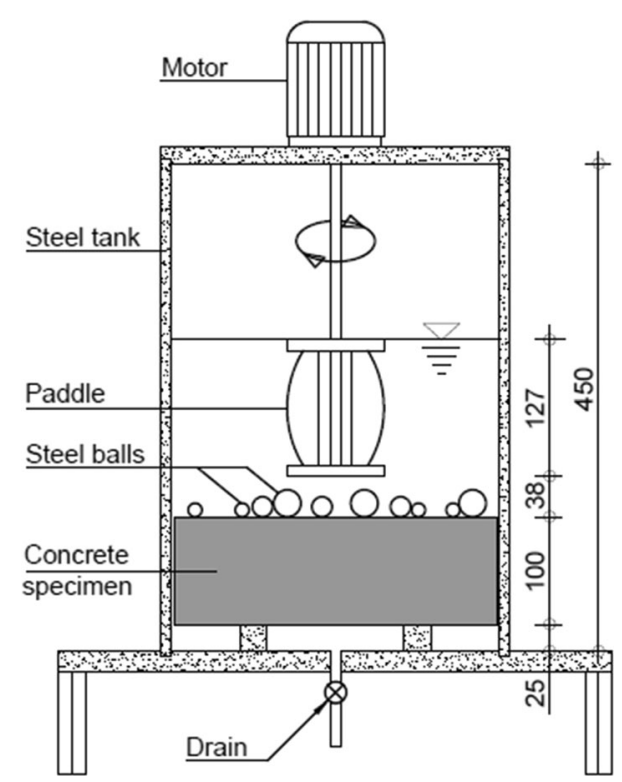

Fig. 3 Experimental setup of the concrete abrasion test

\subsubsection{Mechanical properties}

These properties were included in the scope of the study to monitor the quality of the concretes used and for purposes of examining their relationship with concrete abrasion loss. Compressive strength was determined from 9 concrete cubes of $100 \mathrm{~mm}$ in according to BS EN 12390-3 [44]. In contrast, three cylinders $(100 \phi \times 200 \mathrm{~mm})$ were used to test tensile splitting strength and modulus of elasticity according to BS EN 12390-6 [45] and BS EN 12390-13 [46] respectively.

\subsubsection{Statistical analysis}

A two-step statistical approach was adopted in comparing the performance of BFR concretes to that of the plain concrete mixture. In the first step, effect of BF addition is analysed from the differences in mean together with the coefficients of variation. This enabled comparisons to be made with the findings of past studies [3, 17, 18]. Due to the small number of samples tested for abrasion, compressive strength, tensile splitting strength and modulus of elasticity, the normality of the test data could not be ascertained. Thus, nonparametric tests, viz. Mann-Whitney test and Kruskal Wallis analysis of variance (ANOVA) test [47] were respectively used to compare the results of two, and three or more mixtures. The MannWhitney test [47] was used to determine whether or not there was a significant difference in performance of the plain concrete mixture and each of the BFreinforced concretes. This test is performed by first pooling and ranking the data for each sample. Thereafter, the total sum of the ranks is then computed for each sample, and the $U$ statistic is determined [47]. The $p$-value is then calculated and compared with the significance level [47] to make the decision. The Kruskal-Wallis ANOVA test is also undertaken by each sample group being pooled and ranked. This is followed by calculation of the rank sum for each group and $H$ statistic. The $p$-value is estimated by considering that the $H$-statistic follows the Chi-Square $\left(\chi^{2}\right)$ distribution whose degrees of freedom (DF) are equal to the number of sample groups minus one [47]. The significance level used in the present study (5\%) was based on the adoption of $95 \%$ confidence in consistence with the level typically used to determine the characteristics properties of structural materials [48]. 
The statistical tests used have been adopted by past researchers in the field of concrete research [22, 49-51] with success.

\section{Test results and discussion}

Data from the experimental campaign was used to understand BF-reinforced concrete abrasion mechanisms, the effect of $\mathrm{BF}$ addition to concrete on its abrasion resistance and the relationship between the abrasion resistance and fundamental mechanical properties in BF-reinforced concretes.

\subsection{Modes of concrete abrasion loss}

The abraded surfaces of concrete specimens with different BF contents were examined after each time increment. Figure 4 shows an abrasion-damaged test specimen of mixture FC1.5 after a test duration of $72 \mathrm{~h}$.

Qualitative examinations of the abraded surfaces of all the five concretes revealed that there was no distinction in the surface characteristics exhibited by mixtures with different $\mathrm{BF}$ dosages. In all the concretes tested, the coarse aggregates (CA) were exposed within the first $24 \mathrm{~h}$ of the test after the removal of the matrix surface layer. It was also observed that the rate of the matrix phase abrasion was higher than that of the CA. However, within the 72-h abrasion period, there was no evidence of plucking of CA from the surface of the test specimen. This indicates that in both the plain and BFreinforced concretes used in the investigation, a very good degree of hardness was attained in both the matrix and interfacial transition zone (ITZ). Based on the small size of the BF and dispersion within the matrix, their effect on the abrasion rate of the matrix phase did not seem to be significant. Also, since no anchored BF strands were observed on the surface by the naked eye, this is an indication that they were removed at a rate similar to that of the cement/sand matrix through either fibre breakage, pull-out or de-bonding at the fibrematrix interface.

\subsection{Mechanical and abrasion behaviour of concrete mixtures}

The mechanical properties of the concretes tested are summarised in Table 3 while the results of abrasion

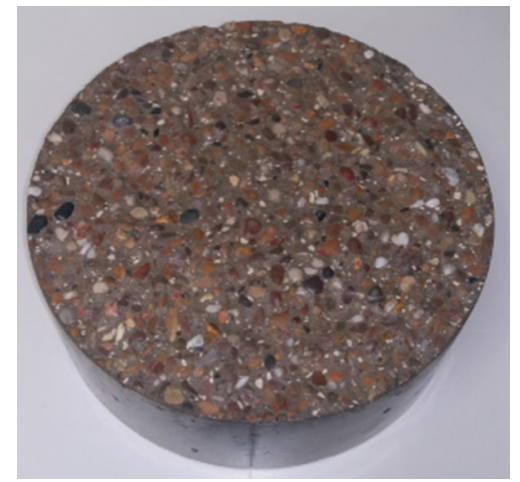

Fig. 4 Abraded test specimen of mixture FC1.5 at $72 \mathrm{~h}$

tests at durations of 24,48 and $72 \mathrm{~h}$ are shown in Fig. 5. The results presented are the means of specimens tested. Further, in Table 4, the differences between the abrasion loss of basalt fibre-reinforced concretes and the plain concrete $(\Delta \mu)$ as well as values of coefficients of variation $(\mathrm{CV})$ are presented.

\subsubsection{Effect of basalt fibre content on concrete abrasion}

In this investigation, concretes with lower abrasion loss are considered to more resistant to the action of waterborne sediments and vice-versa. It can be observed in Table 4 that at the test duration of $24 \mathrm{~h}$, $\mathrm{BF}$ addition in dosages of $0.5,1.5$ and $3.0 \mathrm{~kg} / \mathrm{m}^{3}$, reduced concrete abrasion loss by $1.3 \%$ to $5.9 \%$ while the $\mathrm{BF}$ content of $1 \mathrm{~kg} / \mathrm{m}^{3}$ increased the abrasion loss of concrete by just $1.3 \%$. However, the sample data from which these effects were assessed also exhibited deviations evidenced by the $\mathrm{CV}$ values that varied from $2.7 \%$ to $9.5 \%$. After a 48 -h test period, Table 4 also shows that $\mathrm{BF}$ addition in contents of 0.5 to $1.5 \mathrm{~kg} / \mathrm{m}^{3}$ increased concrete abrasion loss by $5.0 \%$ to $6.5 \%$ respectively while a reduction of $7.2 \%$ was obtained when the BF content was increased to $3 \mathrm{~kg}$ / $\mathrm{m}^{3}$. But as in the 24-h test results, the modest effects of $\mathrm{BF}$ on concrete abrasion resistance were eclipsed by the relatively large $\mathrm{CV}$ values of the data that ranged from $3.7 \%$ to $9.1 \%$. Similarly, the trend exhibited by the 72-h test results was consistent with those at $48 \mathrm{~h}$. At $72 \mathrm{~h}$, the use of 0.5 to $1.5 \mathrm{~kg} / \mathrm{m}^{3} \mathrm{BF}$ resulted in concrete abrasion loss increments of $10.5 \%$ to $14.5 \%$ while at a content of $3 \mathrm{~kg} / \mathrm{m}^{3}$, there was a small reduction in the abrasion loss of $2.6 \%$. The $\mathrm{CV}$ values for this test period varied from $3.1 \%$ to $12.7 \%$. 
Table 3 Mechanical properties of concrete

\begin{tabular}{llll}
\hline Concrete mixture & Compressive Strength $(\mathrm{MPa})$ & Tensile splitting strength $(\mathrm{MPa})$ & Modulus of elasticity $(\mathrm{GPa})$ \\
\hline RC0 & 42.4 & 3.98 & 32.8 \\
FC0.5 & 45.9 & 4.40 & 30.1 \\
FC1.0 & 3.98 & 31.8 \\
FC1.5 & 44.0 & 4.36 & 33.6 \\
FC3.0 & 44.0 & 3.53 & 28.5 \\
\hline
\end{tabular}

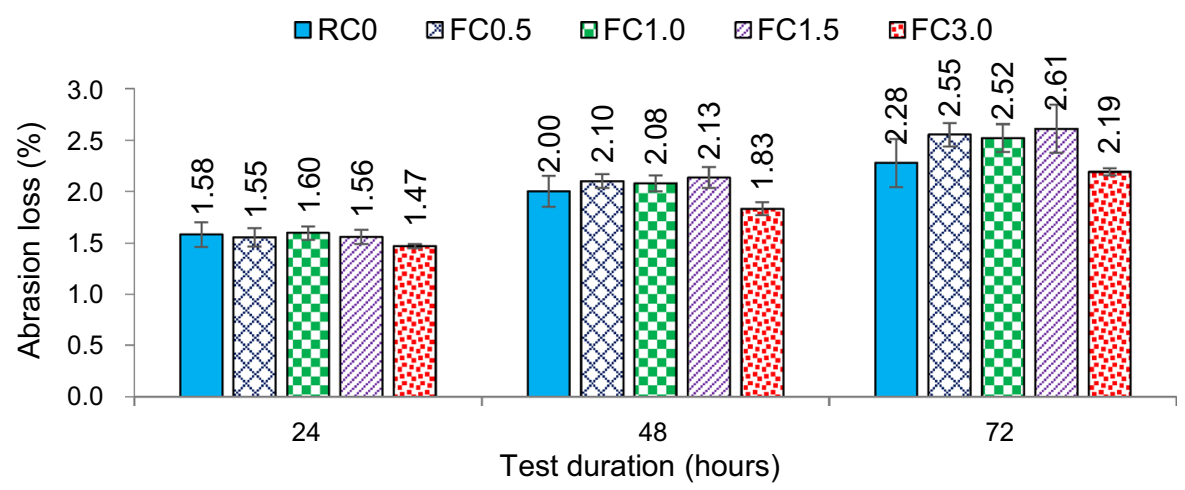

Fig. 5 Abrasion loss of concrete mixtures

Table 4 Coefficients of variation and differences in the mechanical properties and abrasion loss of basalt fibre-reinforced and plain concretes

\begin{tabular}{|c|c|c|c|c|c|c|c|c|c|c|c|c|}
\hline \multirow[t]{4}{*}{ Mixture } & \multicolumn{6}{|c|}{ Mechanical properties } & \multirow{2}{*}{\multicolumn{6}{|c|}{$\frac{\text { Abrasion loss }}{\text { Test duration (h) }}$}} \\
\hline & \multicolumn{2}{|c|}{ Compressive strength } & \multicolumn{2}{|c|}{ Tensile splitting strength } & \multicolumn{2}{|c|}{ Modulus of elasticity } & & & & & & \\
\hline & \multirow[b]{2}{*}{$\mathrm{CV}$} & \multirow[b]{2}{*}{$\Delta \mu$} & \multirow[b]{2}{*}{$\mathrm{CV}$} & \multirow[b]{2}{*}{$\Delta \mu$} & \multirow[b]{2}{*}{$\mathrm{CV}$} & \multirow[b]{2}{*}{$\Delta \mu$} & \multicolumn{2}{|l|}{24} & \multicolumn{2}{|l|}{48} & \multicolumn{2}{|l|}{72} \\
\hline & & & & & & & $\mathrm{CV}$ & $\Delta \mu$ & $\mathrm{CV}$ & $\Delta \mu$ & $\mathrm{CV}$ & $\Delta \mu$ \\
\hline $\mathrm{RC} 0$ & 2.8 & - & 5.2 & - & 3.4 & & 9.5 & - & 9.1 & - & 12.7 & - \\
\hline FC0.5 & 4.8 & +8.3 & 2.0 & +10.6 & 8.1 & -8.2 & 6.9 & -1.3 & 3.7 & +5.0 & 5.5 & +11.8 \\
\hline $\mathrm{FC} 1.0$ & 7.5 & +3.8 & 5.1 & - & 6.8 & -3.0 & 4.9 & +1.3 & 4.6 & +4.0 & 6.5 & +10.5 \\
\hline FC1.5 & 4.2 & +3.8 & 5.9 & +9.8 & 6.1 & +2.4 & 5.5 & -1.3 & 5.8 & +6.5 & 11.0 & +14.5 \\
\hline FC3.0 & 8.1 & -7.1 & 3.0 & -11.6 & 8.7 & -13.1 & 2.7 & -5.9 & 4.3 & -7.2 & 3.1 & -2.4 \\
\hline
\end{tabular}

$(-)$ and $(+)$ in $\Delta \mu$ denote $\%$ reductions and increments respectively

It is clear from the small differences in the abrasion loss of BF-reinforced concrete relative to the control mixture that the effect of $\mathrm{BF}$ use on concrete abrasion resistance is not apparent from the mean values due the large $\mathrm{CV}$ values in the test data of the respective concretes. The Mann-Whitney test whose results are in Table 8 ("Appendix A") was used to determine whether or not the differences were significant for the three test durations. The results indicate that at $95 \%$ confidence, $\mathrm{BF}$ addition in dosages of up to $3 \mathrm{~kg} / \mathrm{m}^{3}$ did not have a significant effect on the abrasion resistance of concrete.

It is important to note that to the best of the authors' knowledge, there have been no published studies on the abrasion resistance of BF-reinforced concretes with the ASTM C1138 method. Therefore, the 
findings of the present study were compared with previous ASTM C1138 test investigations on the abrasion resistance of BF-reinforced mortars and fibre-reinforced concretes containing other types of micro-fibres, as well as studies on BF-reinforced concretes using other abrasion test methods. The ASTM C1138 results in Table 4 are in agreement with those of Kabay [17] for concrete mixtures with $w / c$ of 0.45 evaluated using the Bohme test where negligible reductions in mean abrasion loss of $1.8 \%-4.4 \%$ were found for both 12-24 mm fibre lengths regardless of the BF amount added. However, these suggested improvements in concrete abrasion resistance due to $\mathrm{BF}$ addition were subsumed in the $\mathrm{CV}$ values that varied from $4.6 \%$ to $10.7 \%$ which indicates the insignificance of the reported abrasion resistance improvements. Further comparison with the results of Kabay [17] for concrete mixtures with $w / c$ of 0.60 reveals some disagreement since the use of 12 and $24 \mathrm{~mm}$ long $\mathrm{BF}$ in dosages of 2 and $4 \mathrm{~kg} / \mathrm{m}^{3}$ reduced concrete abrasion loss by $13.9 \%$ and $18.4 \%$ whilst the CV values varied from $2.9 \%$ and $11.9 \%$, which suggest possible significance of the differences in concrete performance. The effect of BF appears to be more prominent in mortars based on the results of Jiang et al. [18] in which the abrasion resistance increments of $14 \%-39 \%$ were reported. In fact, similar effects on the abrasion resistance of mortars with the addition of polypropylene fibres were reported by Abid et al. [19] and Jiang et al. [18] who found enhancements of $20 \%-95 \%$ and $25 \%-77 \%$ respectively. Studies by Horszczaruk [3] and Grdic [13] on concretes reported abrasion resistance increments of $6 \%-29 \%$ due to the addition of polypropylene fibres. However, with the exception of Kabay [17], other workers [3, 13, 19] have not indicated the deviations of their test data from the mean abrasion loss. Based on the fact that the typical $\mathrm{CV}$ of the ASTM C1138 abrasion loss in ordinary concretes can be up to $30 \%[2,34]$, it is difficult to confirm the significance of the reported improvements in abrasion resistance in most past studies. Therefore, based on the results of the present study, it can be concluded that the use of BF in doses of up to $3 \mathrm{~kg} / \mathrm{m}^{3}$ does not have a significant effect on the abrasion resistance of the concrete types examined.

The use of basalt fibres is intuitively expected to improve concrete abrasion resistance due to the tensile strength and modulus of elasticity of basalt fibre being considerably greater that of the reference concrete. The bridging effect of basalt fibres would thus limit the propagation of micro-cracks resulting from the tensile stresses in concrete induced by the impact of waterborne solids. The lack of any major effect on concrete abrasion resistance may firstly be explained by the characteristics of the matrix-fibre interface. Scanning electron microscopy (SEM) of basalt fibre-reinforced concretes has shown that at the age of 28 days, the fibre-matrix interface exhibited a gap and the matrix around the fibre was relatively loose when compared to the configuration at 7 days in which no gap at the interface was observed and a good bond was noticeable at the interface [5]. This could have resulted in the fibre de-bonding under tensile stress resulting in the inability of basalt fibre to form effective bridges across the micro-cracks.

\subsubsection{Normality tests on concrete abrasion loss}

The distribution of the test data is a critical consideration in the selection of an appropriate statistical significance test method. Since the abrasion loss results of all concretes evaluated were found not to be significantly different, the data was deemed to have been drawn from the same population. The normality of data was tested using the Shapiro-Wilks [52] test and results for the three test durations presented in Table 5 .

As seen in Table 5, $p$-values at the three test durations ranged from 0.18 to 0.93 (greater than 0.05 ) which suggests that at $95 \%$ confidence, concrete abrasion loss data was likely to have been drawn from a normally-distributed population. This indicates that parametric instead of nonparametric test methods can be used to determine whether or not differences in the abrasion loss of concrete are significant.

In summary, it would appear that for concretes with $w / c$ of 0.5 , and possibly lower, the use of BF does not have a significant effect on its abrasion resistance, and as such BF addition would not be an effective strategy to increase the abrasion resistance of concretes used in hydraulic structures exposed to sediment-laden flows. Therefore, BF can be confidently used to reduce bleeding, and control plastic and drying shrinkage cracks in concrete without concerns about detrimental effects on its abrasion resistance. Further, abrasion loss in concrete appears to follow a normal distribution for which parametric test methods can be used to test 
the significance of differences between various concrete mixtures.

\subsubsection{Effect of basalt fibre content on mechanical properties}

The absence of a generally accepted parameter to define concrete abrasion resistance coupled with the comparatively cumbersome nature of most abrasion test methods including the ASTM C1138 implies that concrete designers often recourse to its mechanical properties, especially compressive strength to infer its abrasion resistance despite its unreliability at very high-strength [30]. Thus, herein a comparative study of relationship between the abrasion resistance of BF concretes and basic mechanical properties, i.e. compressive strength, tensile splitting strength and modulus of elasticity is undertaken.

The compressive strength test results in Table 3 were used to monitor the quality of concrete of the abrasion test specimens by accompanying each concrete disc with three cubes for compression tests. Based on the fact that each concrete disc was cast separately, the Kruskal-Wallis test [47] was used to determine whether or not the compressive strength of the three concrete casts of each concrete mixture were drawn from the same population as shown in Table 7. The $p$-values obtained (greater than 0.05 ) indicate that at $95 \%$ confidence, the three separate concrete casts of each mixture appear to have come from the same population. This demonstrates that the three different casts of the same mixture can now be used to assess the effect of BF use on its compressive strength. The effect of BF fibre dosage on mechanical properties of concrete are shown in Table 4 while results of MannWhitney tests on the significance of the differences in the mechanical properties are shown in Table 10.

3.2.3.1 Compressive strength It can be observed in Table 4 that addition of BF to concrete in dosages of 0.5 to $1.5 \mathrm{~kg} / \mathrm{m}^{3}$ increased the compressive strength of

Table 5 Shapiro-Wilks test on concrete abrasion loss

\begin{tabular}{llll}
\hline Duration (h) & DF & W-statistic & $p$ value \\
\hline 24 & 15 & 0.92 & 0.18 \\
48 & 15 & 0.93 & 0.27 \\
72 & 15 & 0.98 & 0.93 \\
\hline
\end{tabular}

the specimens by 3.8 to $8.3 \%$ respectively. However, further increment in the BF content to $3 \mathrm{~kg} / \mathrm{m}^{3}$ led to a reduction in compressive strength of $7.1 \%$. Noting that the $\mathrm{CVs}$ of the compressive strength data ranged from $2.8 \%$ to $8.1 \%, \mathrm{BF}$ addition to concrete did not have a clear effect on its compressive strength for the entire range of $\mathrm{BF}$ contents tested. The Mann-Whitney test was used to determine whether or not the compressive strength of plain concrete was significantly different from those of BF-reinforced concretes. Table 10 shows that at $95 \%$ confidence, differences were not significant for all BF-reinforced concretes except for one with $0.5 \mathrm{~kg} / \mathrm{m}^{3}$ content.

For comparison, the results of some past studies on the $\mathrm{BF}$ effect on compressive strength of concrete $[16,17,22]$ are shown in Table 6 . The compressive strength results of the present study are consistent with the conclusions of past studies outlined in Table 6 which suggest that $\mathrm{BF}$ effect on compressive strength is typically within $\pm 10 \%$. The fact that the effect of $\mathrm{BF}$ addition on the compressive strength and abrasion resistance of concrete were both generally determined to be not significant (apart from mixture FC0.5) indicates that the effects of $\mathrm{BF}$ on the two parameters were consistent. This suggests the possible suitability of compressive strength as an indicator for abrasion resistance of concrete materials incorporating BF.

3.2.3.2 Tensile splitting strength Table 4 shows that the use of BF in contents of 0.5 and $1.5 \mathrm{~kg} / \mathrm{m}^{3}$ increased the tensile strength of concrete by $10.6 \%$ and $9.8 \%$ respectively. In contrast, the BF of $1 \mathrm{~kg} / \mathrm{m}^{3}$ showed no effect on the tensile strength while a decrement of $11.6 \%$ was found at BF content of $3 \mathrm{~kg} / \mathrm{m}^{3}$. The fact that the $\mathrm{CV}$ of the tensile strength varied from $2 \%$ to $5.9 \%$ implies that significance of the $\mathrm{BF}$ was not obvious from the mean tensile strength results. The Mann-Whitney test results shown in Table 10 show that at $95 \%$ confidence, there was no evidence that the use of BF fibre in contents of up to $3 \mathrm{~kg} / \mathrm{m}^{3}$ had a significant effect on the tensile strength of concrete. Jiang et al. [5] also found that tensile strength was enhanced by $14.8 \%$ to $25.5 \%$ when BF with $20 \mu \mathrm{m}$ diameter and lengths 12 and $22 \mathrm{~mm}$ was used in amounts that ranged from 1.3 to $13.3 \mathrm{~kg} / \mathrm{m}^{3}$ for concretes with cylinder compressive strengths of 45-48 MPa. The BF with $22 \mathrm{~mm}$ length were found to be marginally more effective in improving tensile strength than the $12 \mathrm{~mm}$. These degrees of increment 
Table 6 Past studies on the effect of basalt fibre on the compressive strength of concrete

\begin{tabular}{|c|c|c|c|c|c|c|c|c|}
\hline \multirow{2}{*}{$\begin{array}{l}\text { Compressive } \\
\text { strength (MPa) }\end{array}$} & \multirow[t]{2}{*}{$w / c$} & \multicolumn{5}{|c|}{ Fibre properties } & \multirow{2}{*}{$\begin{array}{l}\text { Effect on concrete } \\
\text { compressive strength }(\%)\end{array}$} & \multirow[t]{2}{*}{ References } \\
\hline & & $\begin{array}{l}\Phi \\
(\mu \mathrm{m})\end{array}$ & $\begin{array}{l}\text { Length } \\
(\mathrm{mm})\end{array}$ & $\begin{array}{l}\text { Tensile } \\
\text { strength } \\
(\mathrm{MPa})\end{array}$ & $\begin{array}{l}\text { Modulus of } \\
\text { elasticity (GPa) }\end{array}$ & $\begin{array}{l}\text { Dose } \\
\left(\mathrm{kg} / \mathrm{m}^{3}\right)\end{array}$ & & \\
\hline $63-67$ & 0.50 & $\begin{array}{l}13 ; \\
20\end{array}$ & 12 & $4450 \pm 350$ & 89 & $6.8-27$ & -0.4 to $+5.1 \%$ & $\begin{array}{l}\text { Kizilkanat } \\
{[16]^{\mathrm{a}}}\end{array}$ \\
\hline $34-38$ & 0.50 & 16 & $36 ; 50$ & No data & No data & 4 & -9.3 to $+1.3 \%$ & Branston \\
\hline $38-40$ & & & & & & 8 & +2.9 to $+4.2 \%$ & et al. $[22]^{\mathrm{b}}$ \\
\hline $38-39$ & & & & & & 12 & -0.3 to $+2.1 \%$ & \\
\hline $45-49$ & 0.60 & 13 & $12 ; 24$ & $4450 \pm 350$ & 89 & 2 to 4 & -4.5 to $-9.3 \%$ & Kabay $[17]^{\mathrm{c}}$ \\
\hline $57-69$ & 0.45 & 20 & & & & & -8.4 to $-17.9 \%$ & \\
\hline
\end{tabular}

Test specimen descriptions: $a=150 \mathrm{~mm}$ cubes; $b=100 \phi / 200 \mathrm{~mm}$ cylinders; $c=100 \mathrm{~mm}$ cubes

in tensile strength were also found by Algin and Ozen [53] who found the optimal BF dosage to be about $13.9 \mathrm{~kg} / \mathrm{m}^{3}$ which resulted in $15 \%$ increase in tensile strength. The trend of improved tensile strength was also reported by Kizilkanat et al. [16] who found $40 \%$ improvement in tensile strength due to addition of $27 \mathrm{~kg} / \mathrm{m}^{3}$ of BF. It appears the random variations in tensile strength found in the present study are due to modest quantities of BF used compared to the high dosages adopted in some studies [5, 53] in literature. It was also notable that effect of BF on concrete abrasion and tensile strength was consistent because for the dosages used, the effect of BF was found to be insignificant for both parameters.

3.2.3.3 Modulus of elasticity The values of modulus of elasticity in Table 3 from the experimental campaign were first validated with the established empirical relation with compressive strength proposed in the BS EN 1992-1-1 [54]. The modulus of elasticity values predicted from the empirical relations were found to deviate from measured results by $2.8 \%$ to $13.0 \%$ which indicates the reasonable accuracy of the modulus of elasticity test results. The effects of incorporation of various BF dosages on the modulus of elasticity of concrete are also presented in Table 4 . The results show that use of BF in contents of up to $3 \mathrm{~kg} / \mathrm{m}^{3}$ generally reduced the modulus of elasticity of concrete by $3 \%$ to $13.1 \%$ with the exception of the dose of $1.5 \mathrm{~kg} / \mathrm{m}^{3}$ where there was an increase of just $2.4 \%$. The CV of the modulus of elasticity of the concrete mixtures varied from $3.4 \%$ to $8.7 \%$ which meant that the effect of $\mathrm{BF}$ use on the modulus of elasticity of concrete was not clear from the mean values. Based on Mann-Whitney tests whose results are in Table 10, no evidence of the significance of the difference between the modulus of elasticity of the control mixture and BF-reinforced concretes was found at $95 \%$ confidence. This conclusion seems to agree with the results of Kizilkanat et al. [16] and Ayub et al. [14]. Kizilkanat et al. [16] found that the modulus of elasticity of concrete generally reduced by up to $5.2 \%$ on addition of $\mathrm{BF}$ but the fact that the deviation in the data $(\mathrm{CV})$ varied by $2.8 \%$ to $7.2 \%$ indicates that the effects could not have been significant. Therefore, the effect of $\mathrm{BF}$ use on the modulus of elasticity of concrete is also consistent with its impact on the abrasion resistance.

In summary, it appears that use of up to $3 \mathrm{~kg} / \mathrm{m}^{3}$ of BF in concrete does not have a significant effect on its abrasion resistance, as well as compressive strength, tensile splitting strength and modulus of elasticity. The correlation between the abrasion resistance and each mechanical property of concrete is thus presented in Sect. 3.3.

\subsection{Dependence of abrasion loss on mechanical properties}

This was undertaken to compare the suitability of compressive strength, tensile splitting strength and modulus of elasticity of concrete to predict its abrasion loss. The variations of abrasion loss with the three fundamental mechanical properties are shown in Figs. 6, 7, 8. The appropriate form of the relationship selected after evaluation of linear, exponential, power, 


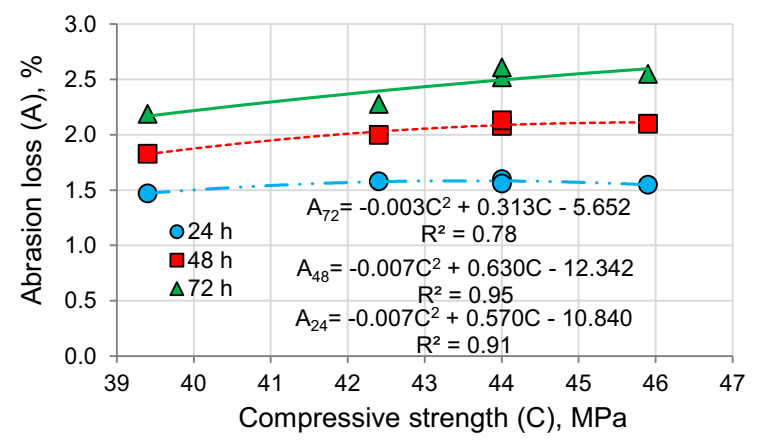

Fig. 6 Relationship between concrete abrasion loss and compressive strength

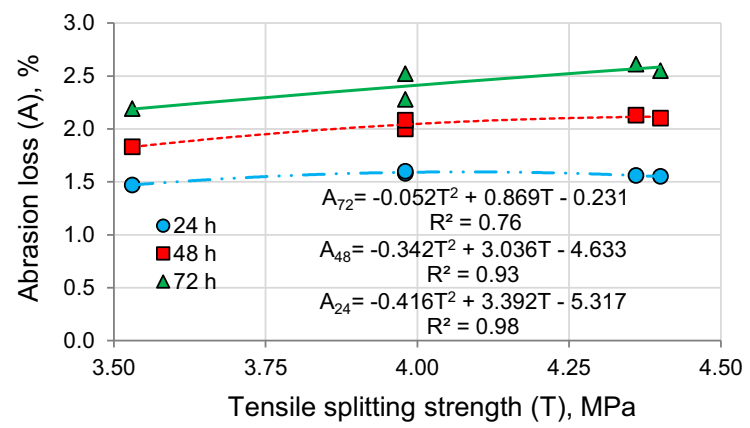

Fig. 7 Relationship between concrete abrasion loss and tensile splitting strength

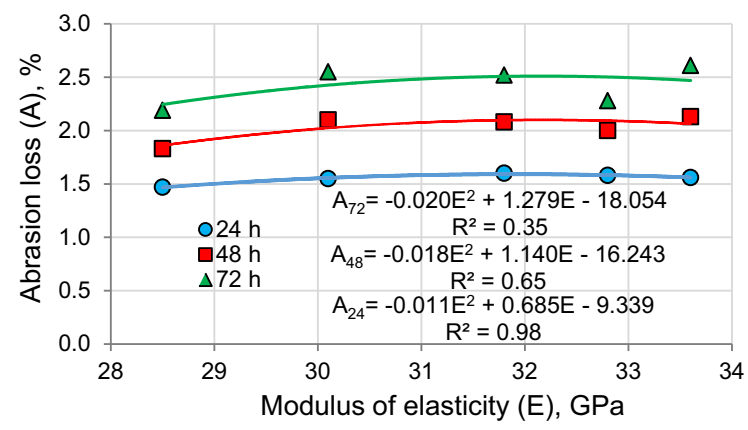

Fig. 8 Relationship between concrete abrasion loss and modulus of elasticity

logarithmic and polynomial functions based on the values of coefficients of determination $\left(R^{2}\right)$. It was established that concrete abrasion loss was best described by polynomial functions of compressive strength, tensile splitting strength and modulus of elasticity with $R^{2}$ ranges of $78.1 \%$ to $95.5 \%, 76.5 \%$ to $98.0 \%$ and $35.1 \%$ to $98.6 \%$ respectively over the three test durations.
The values $R^{2}$ in Figs. 6, 7, 8 indicate that compressive and tensile splitting strengths explained the largest variations in concrete abrasion loss compared to modulus of elasticity. This suggests that both compressive and tensile splitting strengths could be suitable for use as parameters for prediction of the ASTM C1138 abrasion loss in BF-reinforced concretes. The significance of the relationships defined by the regression equations in Figs. 6, 7, 8 were examined using an $F$-test [47] as shown in Table 7.

The results in Table 7 show that at $95 \%$ confidence, the relationship between concrete abrasion loss and mechanical properties only appeared to be significant $(p<0.05)$ at the test duration of $48 \mathrm{~h}$ for compressive strength, and $24 \mathrm{~h}$ for both tensile splitting strength and modulus of elasticity. There was no evidence of a significant relationship $(p>0.05)$ at the rest of the test durations for all the mechanical properties of concrete tested. This lack of consistency in the significance of the relations proposed in Figs. 6, 7, 8 over all the test durations can be attributed to BF not having a considerable effect on both its abrasion resistance and mechanical properties.

\section{Summary and conclusions}

In this study, the ASTM C1138 test was used to examine the effect of the addition of basalt micro-fibre on the abrasion resistance of a concrete of the type applicable to hydraulic structures. Concrete mixtures incorporating fibre in contents of 0 to $3.0 \mathrm{~kg} / \mathrm{m}^{3}$ were subjected to abrasion. The fundamental mechanical properties of the concretes comprising of compressive and tensile splitting strengths, as well as modulus of elasticity were also tested. Statistical tests were used to determine whether or not fibre addition had a significant effect on concrete abrasion resistance and mechanical properties. Based on the concrete, fibre type and dosages examined here, the following key conclusions can be drawn:

1. The addition of basalt micro-fibres to concrete mixtures in contents of up to $3 \mathrm{~kg} / \mathrm{m}^{3}$ does not have a significant effect on its abrasion resistance. Furthermore, concrete abrasion loss appears to follow a normal distribution.

2. Basalt micro-fibre in doses of up to $3 \mathrm{~kg} / \mathrm{m}^{3}$ does not have a significant effect on the compressive 
Table 7 Results of $F$-tests on regression models

DF denotes degrees of freedom for the model and error

\begin{tabular}{llccc}
\hline Mechanical parameter & Duration $(\mathrm{h})$ & DF & $F$-statistic & $p$ value \\
\hline Compressive strength & 24 & 2,2 & 10.74 & 0.085 \\
& 48 & & 19.37 & 0.049 \\
Tensile splitting strength & 72 & & 3.57 & 0.219 \\
& 24 & 2,2 & 48.40 & 0.020 \\
Modulus of elasticity & 48 & & 14.70 & 0.064 \\
& 72 & & 3.25 & 0.235 \\
& 24 & 2,2 & 72.86 & 0.014 \\
& 48 & & 1.90 & 0.345 \\
& 72 & & 0.54 & 0.649 \\
\hline
\end{tabular}

and tensile splitting strengths, as well as modulus of elasticity of concrete. This suggests that basalt micro-fibre effects on concrete mechanical properties is consistent with that on abrasion resistance.

3. There was no consistency in the significance of the relations between abrasion loss and mechanical properties of concrete across all the test durations used. The proposed relation based on compressive strength was found to be significant at a test duration of $48 \mathrm{~h}$ and tensile splitting strength and modulus of elasticity at $24 \mathrm{~h}$.

4. At dosages of up to $3 \mathrm{~kg} / \mathrm{m}^{3}$, basalt micro-fibre addition can be considered to have a generally neutral effect. Thus, basalt micro-fibres could be used for the other potential benefits they may bring such as control of bleeding, plastic and shrinkage cracking in concrete for hydraulic structures without having deleterious effects on its abrasion resistance.

Funding This research is funded through the Technical $\mathrm{PhD}$ Studentship of the Department of Mechanical, Aerospace and Civil Engineering (MACE), University of Manchester, the authors wish to express their gratitude and sincere appreciation. Acknowledgements are also due to Basalt Technologies UK Ltd for supplying the basalt micro-fibre used, Mr Paul Nedwell and Mr John Mason (MACE) for their invaluable advice and assistance with the experimental work.

Code availability Not applicable.

Availability of data and material Available on request.

\section{Declarations}

Conflicts of interest The authors declare that they have no conflicts of interest.

Open Access This article is licensed under a Creative Commons Attribution 4.0 International License, which permits use, sharing, adaptation, distribution and reproduction in any medium or format, as long as you give appropriate credit to the original author(s) and the source, provide a link to the Creative Commons licence, and indicate if changes were made. The images or other third party material in this article are included in the article's Creative Commons licence, unless indicated otherwise in a credit line to the material. If material is not included in the article's Creative Commons licence and your intended use is not permitted by statutory regulation or exceeds the permitted use, you will need to obtain permission directly from the copyright holder. To view a copy of this licence, visit http://creativecommons.org/licenses/by/4.0/. 


\section{Appendix A}

See Tables 8, 9, 10 .

Table 8 Mann-Whitney test results on abrasion loss

Table 9 Kruskal-Wallis tests on compressive strength

\begin{tabular}{|c|c|c|c|c|c|c|}
\hline \multirow[t]{2}{*}{ Concrete mixture } & \multicolumn{2}{|c|}{$24 \mathrm{~h}$} & \multicolumn{2}{|c|}{$48 \mathrm{~h}$} & \multicolumn{2}{|c|}{$72 \mathrm{~h}$} \\
\hline & $U$ & $p$ value & $U$ & $p$ value & $U$ & $p$ value \\
\hline $\mathrm{FC} 0.5$ & 5 & 1 & 4 & 1 & 2 & 0.4 \\
\hline $\mathrm{FC} 1.0$ & 4 & 1 & 3.5 & 0.8 & 1 & 0.2 \\
\hline $\mathrm{FC} 1.5$ & 4.5 & 1 & 2 & 0.4 & 1 & 0.2 \\
\hline FC3.0 & 7 & 0.4 & 7 & 0.4 & 5.5 & 0.8 \\
\hline
\end{tabular}

\begin{tabular}{lllll}
\hline Mixture & Sample size & $\mathrm{X}^{2}$ & DF & $p$ value \\
\hline RC0 & 9 & 4.3 & 2 & 0.116 \\
FC0.5 & & 5.7 & & 0.058 \\
FC1.0 & 6.0 & & 0.051 \\
FC1.5 & & 3.1 & & 0.211 \\
FC3.0 & 2.8 & & 0.252 \\
\hline
\end{tabular}

Table 10 Mann-Whitney tests on mechanical properties of concrete

\begin{tabular}{llllll}
\hline Mechanical property & Statistic & \multicolumn{2}{l}{ Concrete mixture } \\
\cline { 3 - 6 } & & BF0.5 & BF1.0 & BF1.5 & BF3.0 \\
\hline Compressive strength & $U$ & 7.5 & 33 & 19 & 61.5 \\
& $p$ value & 0.002 & 0.534 & 0.059 & 0.066 \\
Tensile splitting strength & $U$ & 0 & 4.5 & 0.5 & 9 \\
& $p$ value & 0.1 & 1 & 0.2 & 0.1 \\
Modulus of elasticity & $U$ & 8 & 5 & 4 & 9 \\
& $p$ value & 0.2 & 1 & 1 & 0.1 \\
\hline
\end{tabular}

\section{References}

1. Liu TC, McDonald JE (1981) Abrasion-erosion resistance of fiber-reinforced concrete. Cem Concr Aggregates 3:93-100

2. Sonebi M, Khayat K (2001) Testing abrasion resistance of high-strength concrete. Cem Concr Aggregates 23:34-43

3. Horszczaruk EK (2009) Hydro-abrasive erosion of high performance fiber-reinforced concrete. Wear 267:110-115. https://doi.org/10.1016/j.wear.2005.02.079

4. Sharma S, Arora VV, Kumar S et al (2018) Durability study of high-strength steel fiber-reinforced concrete. ACI Mater J 115:219-225. https://doi.org/10.14359/51701122
5. Jiang C, Fan K, Wu F, Chen D (2014) Experimental study on the mechanical properties and microstructure of chopped basalt fibre reinforced concrete. Mater Des 58:187-193. https://doi.org/10.1016/j.matdes.2014.01.056

6. ACI Committee 544 (2018) Guide for Design with FiberReinforced Concrete. American Concrete Institute, Farmington Hills

7. The Concrete Society (2007) Guidance on the design of steel fibre-reinforced concrete. The Concrete Society, Surrey

8. The Concrete Society (2007) Guidance on the use of macrosynthetic fibre-reinforced concrete: Technical Report No. 65. Surrey 
9. Branston J, Das S, Kenno SY, Taylor C (2016) Influence of basalt fibres on free and restrained plastic shrinkage. Cem Concr Compos 74:182-190. https://doi.org/10.1016/j. cemconcomp.2016.10.004

10. Bell F (1983) Fundamentals of engineering geology, 1st edn. Butterworths, London

11. Fiore V, Scalici T, Di Bella G, Valenza A (2015) A review on basalt fibre and its composites. Compos Part B Eng 74:74-94. https://doi.org/10.1016/j.compositesb.2014.12. 034

12. Sim J, Park C, Moon DY (2005) Characteristics of basalt fiber as a strengthening material for concrete structures. Compos Part B Eng 36:504-512. https://doi.org/10.1016/j. compositesb.2005.02.002

13. Grdic ZJ, Curcic GAT, Ristic NS, Despotovic IM (2012) Abrasion resistance of concrete micro-reinforced with polypropylene fibers. Constr Build Mater 27:305-312. https://doi.org/10.1016/j.conbuildmat.2011.07.044

14. Ayub T, Shafiq N, Nuruddin MF (2014) Mechanical properties of high-performance concrete reinforced with basalt fibers. Proc Eng 77:131-139. https://doi.org/10.1016/j. proeng.2014.07.029

15. Wang D, Ju Y, Shen H, Xu L (2019) Mechanical properties of high performance concrete reinforced with basalt fiber and polypropylene fiber. Constr Build Mater 197:464-473. https://doi.org/10.1016/j.conbuildmat.2018.11.181

16. Kizilkanat AB, Kabay N, Akyüncü V et al (2015) Mechanical properties and fracture behavior of basalt and glass fiber reinforced concrete: an experimental study. Constr Build Mater 100:218-224. https://doi.org/10.1016/j. conbuildmat.2015.10.006

17. Kabay N (2014) Abrasion resistance and fracture energy of concretes with basalt fiber. Constr Build Mater 50:95-101. https://doi.org/10.1016/j.conbuildmat.2013.09.040

18. Jiang C, Huang S, Zhu Y et al (2016) Effect of polypropylene and basalt fiber on the behavior of mortars for repair applications. Adv Mater Sci Eng 2016:14-16. https://doi. org/10.1155/2016/5927609

19. Abid SR, Hilo AN, Daek YH (2018) Experimental tests on the underwater abrasion of engineered cementitious composites. Constr Build Mater 171:779-792. https://doi.org/ 10.1016/j.conbuildmat.2018.03.213

20. Hossain KMA, Lachemi M, Sammour M, Sonebi M (2013) Strength and fracture energy characteristics of self-consolidating concrete incorporating polyvinyl alcohol, steel and hybrid fibres. Constr Build Mater 45:20-29. https://doi.org/ 10.1016/j.conbuildmat.2013.03.054

21. Noushini A, Samali B, Vessalas K (2013) Effect of polyvinyl alcohol (PVA) fibre on dynamic and material properties of fibre reinforced concrete. Constr Build Mater 49:374-383. https://doi.org/10.1016/j.conbuildmat.2013. 08.035

22. Branston J, Das S, Kenno SY, Taylor C (2016) Mechanical behaviour of basalt fibre reinforced concrete. Constr Build Mater 124:878-886. https://doi.org/10.1016/j.conbuildmat. 2016.08.009

23. Çelik Z, Bingöl AF (2020) Fracture properties and impact resistance of self-compacting fiber reinforced concrete (SCFRC). Mater Struct. https://doi.org/10.1617/s11527020-01487-8
24. Girgin ZC, Yildirim MT (2016) Usability of basalt fibres in fibre reinforced cement composites. Mater $S$ 2016:3309-3319. https://doi.org/10.1617/s11527-0150721-4

25. ACI Committee 207 (2017) Report on the erosion of concrete in hydraulic structures. American Concrete Institute, Farmington Hills

26. Allen RT, Terrett F (1968) Durability of concrete in coast protection works. Coast Eng 1:1200-1210

27. McDonald JE, Liu TC (1979) Repair of concrete surfaces subjected to abrasion erosion damage. AEWES, Vicksburg

28. Kryžanowski A, Mikoš M, Šušteršič J, Planinc I (2009) Abrasion resistance of concrete in hydraulic structures. ACI Mater J 106:349-356

29. Cunningham LS, Farrington B, Doherty A (2015) Briefing: abrasion performance of concrete in coastal structures. Proc Inst Civ Eng Marit Eng 168:157-161. https://doi.org/10. 1680/jmaen.15.00011

30. Omoding N, Cunningham LS, Lane-Serff GF (2020) Review of concrete resistance to abrasion by waterborne solids. ACI Mater J 117:

31. DIN 52108 (2010) Testing of inorganic non-metallic materials-wear test using the grinding wheel according to Boehme-grinding wheel method. DIN

32. ASTM C1138 (2012) Standard test method for abrasion resistance of concrete (Underwater method ). ASTM International, West Conshohocken

33. Liu TC (1980) Maintenance and preservation of concrete structures: Report 3-Abrasion-erosion resistance of concrete. US Waterways Experiment Station, Vicksburg

34. Liu TC (1981) Abrasion resistance of concrete. ACI J 78:341-350

35. Kiliç A, Atiş CD, Teymen A et al (2008) The influence of aggregate type on the strength and abrasion resistance of high strength concrete. Cem Concr Compos 30:290-296. https://doi.org/10.1016/j.cemconcomp.2007.05.011

36. Horszczaruk E (2005) Abrasion resistance of high-strength concrete in hydraulic structures. Wear 259:62-69. https:// doi.org/10.1016/j.wear.2005.02.079

37. BS EN 197-1 (2011) Cement. Composition, specifications and conformity criteria for common cements. British Standards Institution, London

38. BS EN 12620 (2002) Aggregates for concrete. British Standards Institution, London

39. Teychenne D, Nicholls J, Franklin R, Hobbs D (1997) Design of normal concrete mixes, 2nd edn. Building Research Establishment, Watford

40. BS 6349-1-4 (2013) Maritime works: general-code of practice for materials. British Standards Institution, London

41. BS EN12350-2 (2019) Testing fresh concrete Part 2: Slump test. British Standards Institution, London

42. Cunningham L, Robertshaw G, Pomfret M (2012) Blackpool central area coast protection scheme, UK. Proc Inst Civ Eng Marit Eng 165:21-29. https://doi.org/10.1680/maen. 2012.165.1.21

43. Cunningham L, Burgess A (2012) Design and construction of the tower headland wave walls, Blackpool, UK. Proc Inst Civ Eng Civ Eng 165:171-178. https://doi.org/10.1680/ cien. 12.00007 
44. BS EN 12390 (2009) Testing hardened concrete. Compressive strength of test specimens, British Standards Institution, London

45. EN 12390-6 BS (2009) Testing hardened concrete. Tensile splitting strength of test specimens, British Standards Institution, London

46. BS EN 12390-13 (2013) Testing hardened concrete. Determination of secant modulus of elasticity in compression, British Standards Institution, London

47. Hayter A (2012) Probability and statistics for engineers and scientists, 4th edn. Brooks/Cole, Boston

48. EN BS 1990 (2002) Eurocode-basis of structural design. British Standards Institution, London

49. Proverbio E (2001) Stability of reference electrodes embedded in concrete: astatistical evaluation. Mag Concr Res 53:225-232

50. Cross WM, Sabnis KH, Kjerengtroen L, Kellar JJ (2000) Microhardness testing of fiber-reinforced cement paste. ACI Mater J 97:162-167
51. Hasparyk NP, Monteiro PJM, Carasek H (2000) Effect of silica fume and rice husk ash on alkali-silica reaction. ACI Mater J 97:486-492

52. Miller RI, Freund EJ, Johnson R (1990) Probability and statistics for engineers, 4th edn. Prentice Hall, New Jersey

53. Algin Z, Ozen M (2018) The properties of chopped basalt fibre reinforced self-compacting concrete. Constr Build Mater 186:678-685. https://doi.org/10.1016/j.conbuildmat. 2018.07.089

54. BS EN 1992-1-1 (2004) Eurocode 2-Design of concrete structures. Part 1-1: General rules and rules for buildings. British Standards Institution, London

Publisher's Note Springer Nature remains neutral with regard to jurisdictional claims in published maps and institutional affiliations. 